1 Universidade Federal do Espírito Santo (Ufes), Centro de Ciência da Saúde, Programa de Pós-graduação em Saúde Coletiva - Vitória (ES), Brasil.

edutonole@yahoo.com.br

2 Universidade Federal do Espírito Santo (Ufes), Centro de Ciências da Saúde, Programa de Pós-graduação em Saúde Coletiva - Vitória (ES), Brasil.

ritacdl@uol.com.br

3 Universidade Federal do Espírito Santo (Ufes), Centro de Ciências da Saúde, Programa de Pós-graduação em Saúde Coletiva - Vitória (ES), Brasil.

geliandrade@hotmail.com

\section{Reflexões sobre análise de implementação de políticas de saúde}

\author{
Reflections on implementation analysis of health policies
}

\author{
Eduardo Tonole Dalfior ${ }^{\mathbf{1}}$, Rita de Cássia Duarte Lima ${ }^{2}$, Maria Angélica Carvalho Andrade ${ }^{\mathbf{3}}$
}

RESUMO A operacionalização da política apresenta inúmeros entraves no nível local permeados por questões estratégicas, por interesses e por múltiplos atores, considerados aspectos determinantes para o sucesso ou insucesso da política. A partir da revisão da literatura, este artigo destaca alguns dilemas e questões problemáticas nas concepções e ideias sobre o processo de implementação de políticas de saúde. Para a base teórica, buscou-se refletir sobre a complexidade dessa temática e sobre alguns aspectos das políticas públicas, da análise das políticas públicas e do processo de implementação de políticas públicas, a partir do campo da produção de conhecimentos, no âmbito da saúde coletiva.

PALAVRAS-CHAVE Políticas públicas; Políticas públicas de saúde; Análise qualitativa.

ABSTRACT The operationalization of the policy presents numerous obstacles on local level permeated by strategic issues, interests and multiple actors, considered key aspects for the success or failure of the policy. Based on the literature review, this article highlights some dilemmas and problematic issues in the conceptions and ideas about the process of implementation of health policies. For the theoretical basis, we sought to reflect on the complexity of this theme and on some aspects of the public policy, of the analysis of public policies and the implementation process of public policy, from the field of knowledge production in the context of public health.

KEYWORDS Public policies; Health public policies; Qualitative analysis. 


\section{Introdução}

A implementação de uma política pública de saúde exige sua tradução em uma política institucional, conceituada como a resposta social (ação ou omissão) de uma organização diante das condições de saúde dos indivíduos e das populações e seus determinantes, e que expressa dimensões de poder e de diretrizes (PAIM; TEIXEIRA, 2006).

A municipalização, decorrente da descentralização do Sistema Único de Saúde (SUS), fez do município o principal espaço para implementar as políticas de saúde. A conformação de cada um dos cenários locais influencia a extensão da implementação e sua efetividade (SOLLA, 2010).

Estudos sobre a descentralização do sistema de saúde no Brasil destacam as complexas relações intergovernamentais na formulação e implementação das políticas de saúde, fortemente induzidas pelo governo federal, mediante mecanismos de transferências de recursos em função da adesão a uma política (ARRETCHE, 2003; MARQUES; MENDES, 2003).

Dada a amplitude territorial brasileira, tal como a complexidade dos territórios em assumir o comando das ações de saúde descentralizadas nos últimos anos, as políticas prioritárias que são definidas em nível da macrogestão do governo, precisam passar por um amplo processo de aceitação ou rejeição por parte dos agentes que farão a implementação dessa política em nível local. Assim, a análise desse processo de implementação torna-se fundamental para compreender por que algumas políticas são mais ou menos eficientes que outras.

O objetivo deste artigo é destacar alguns dos dilemas e aspectos problemáticos nas concepções e ideias sobre o processo de implementação de políticas de saúde. Enfatizam-se, também, as dificuldades na análise de políticas públicas em nível local, sem considerar algumas possibilidades de intervenção no movimento real do processo de implementação. Para a abordagem teórica da temática, considerou-se necessária apresentação e reflexão sobre alguns aspectos das políticas públicas, da análise das políticas públicas e do processo de implementação de políticas públicas, a partir do campo da produção de conhecimentos, no âmbito da saúde coletiva.

\section{Políticas públicas}

As políticas públicas de saúde têm ocupado um lugar central na área da saúde coletiva. Dentre as suas características destacam-se a capacidade de constituir-se em um campo de conhecimento de práticas que envolvem perspectivas de análises e ao mesmo tempo permite avançar na produção do conhecimento e orientar as ações e a formulação das políticas de saúde. O que chama atenção é que as políticas de saúde consistem em um campo do conhecimento da área das ciências humanas que estabelece outro padrão de relação entre o sujeito e o objeto do conhecimento que não aquele próprio das áreas das ciências biológicas e exatas. Vale dizer que trata da produção do conhecimento que busca estabelecer relações entre fenômenos criteriosamente coletados e selecionados (COHN, 2009).

As políticas públicas interferem diretamente na vida dos cidadãos e profissionais e estão sujeitas a múltiplos determinantes, muitas vezes contraditórios, em decorrência de múltiplos interesses envolvidos na determinação dos rumos e formato das políticas públicas (FLEURY; OUVERNEY, 2008).

O debate acerca da temática das políticas públicas no campo da saúde coletiva tem sido realizado a partir de diferentes perspectivas e a primeira questão a ser considerada é sua historicidade. Nesse sentido, Souza (2006) aponta que não existe uma forma única ou mais apropriada para se definir políticas públicas, e, para isso baseia-se nas definições tradicionais de alguns autores como Mead, Lynn, Peters e Dye, que se dedicam a estudar 
esse tema. Para esses autores, segundo Souza (2006), política pública é definida como um campo dentro do estudo da política que analisa o governo à luz de grandes questões públicas, afirmando-a como um conjunto de ações de governo que irão produzir efeitos específicos. Nesse sentido, política pública é entendida como a soma das atividades dos governos, que agem diretamente ou por meio de delegação, e que influenciam a vida dos cidadãos, ou seja, é o que o governo escolhe fazer ou não fazer.

Atualmente, boa parte da literatura entende a política pública como uma ciência do Estado, ou ciência política, e passa a indicar o conjunto de atividades que têm como termo de referência o Estado (Bоввı, 1998 APUD VIANA; BAPTISTA, 2009). Nessa perspectiva, a política deve ser compreendida de forma mais ampla, uma vez que contempla o que o Estado faz (sua dimensão facilmente percebida), bem como aquilo que ele deixa de fazer, refletindo o comportamento dos atores que atuam nesse processo (SERAFIM; DIAS, 2012). Claramente, a política pública se expressa como um fenômeno complexo, que envolve uma série de decisões tomadas por pessoas e organizações dentro do governo, mas influenciadas por outros atores que operam dentro ou fora do Estado (HOWLETT ET AL., 2009 APUD CONTARATO, 2011).

Dessa forma, a política pública é inerente aos Estados, às pessoas e às instituições, sendo compreendida como uma atividade sobre a qual as pessoas fazem, preservam e corrigem as regras sob as quais vivem, não havendo separação entre conflito e cooperação, em que são mediados os valores e as opiniões divergentes, as necessidades e os interesses. É nesse sentido que a política é entendida como tudo aquilo que diz respeito à cidade e ao cidadão urbano, civil, público, sociável e social e seu conceito estritamente relacionado ao poder (BOBBIO, 1998 APUD VIANA; BAPTISTA, 2009).

Um referencial estratégico de investigação sobre o poder é desenvolvido por Bobbio, Mattuci e Pasquito (1998), que entendem que o poder pode ir desde a capacidade geral de agir, até a capacidade do homem em influenciar o comportamento humano.

As definições e conceituações mostram-se bastante diversas, mas, é possível assinalar que falar de política pública é falar de Estado, de pacto social, de interesses e também de poder. Falar de política é, ainda, falar de Estado em ação, do processo de construção de uma ação governamental para um setor, envolvendo recursos, atores, arenas, ideias e negociações (VIANA; BAPTISTA, 2009). É nesse ponto de análise, no qual reside a relação entre os diversos sentidos de política pública com a percepção que se tem do Estado (SERAFIM; DIAS, 2012), que se reconhece a política pública como um objeto sobre o qual se lança um olhar que permite refletir sobre os diferentes interesses, cultura, poder e disputas (LACLAU, 2011 APUD LOPEZ; MOREIRA, 2013).

Ressalta-se ainda que a ação dinâmica e multidirecionada da política pública e o processo de tomada de decisão no momento de construção de uma dada política têm se constituído em objetos principais de análise, em cujos objetivos consistem questionar a ação pública, seus determinantes, suas finalidades, seus processos e suas consequências (VIANA; BAPTISTA, 2009), cada vez mais, atraindo a atenção de diversos grupos, dentre esses, gestores e pesquisadores, que procuram compreender as diversas formas assumidas na relação Estado-sociedade (SERAFIM; DIAS, 2012).

Nesse contexto, para Baptista e Mattos (2011) é importante destacar que o sentido de política usualmente utilizado e que atravessa nossas práticas, muitas vezes, está associado apenas às práticas de governos e às instituições estatais. De acordo com esses autores, esse é um sentido de política que usualmente prevalece, no entanto não é o único. O conceito de Estado, historicamente, foi sendo definido partindo-se da ideia de delimitar uma diferença entre os governantes e governados, sendo o Estado aquele que atuaria na intermediação de 
interesses com vistas ao estabelecimento da ordem para o bem comum. Nesse sentido, o Estado está fortemente ligado à política, o que pode justificar a sua associação às instituições estatais. Comumente, o conceito de política pública é definido como as respostas dos governos às demandas, problemas e conflitos que surgem de um grupo social, sendo esse o produto das negociações entre os diferentes interesses, mediado pela racionalidade técnica dos 'fazedores de política', com vistas à manutenção de uma ordem. Nesse entendimento as políticas públicas passam a ser reduzidas a um processo político racional, gerido pelos representantes do Estado.

Porém, ao discutir as políticas públicas, Baptista e Mattos (2011) apontam para a necessidade de romper com uma visão normativa e descritiva das políticas e trazer o que há de vida na sua construção, ou seja, torna-se necessário ir além do modo formal de definição de Estado e de políticas públicas e buscar nas práticas sociais as formas de construção das políticas públicas em cada contexto. Portanto, o Estado pode ser compreendido como mediador dos interesses sociais, mas também como a expressão da cultura, dos hábitos, das práticas e dos costumes de uma sociedade. Deve-se, então, buscar contribuir para a formação do pensamento político crítico, em que a análise das políticas possa valorizar os processos e os sujeitos, que são os portadores de saber e poder, envolvidos na construção da ação política governamental e não governamental, que produzem efeitos para a sociedade, não sendo restrito aos enunciados oficiais ou institucionais formais. Dessa forma, para esses autores,

a análise de políticas se interessa também pelas formas de intervenção adotadas historicamente pelas instituições, pelas relações entre atores públicos e privados, pela sociedade civil, pelos pactos, objetivos, metas e perspectivas dos diferentes grupos sociais em disputa, os conceitos e sentidos de política. (BATISTA; MATOS, 2011A, P. 65).

\section{Análise de políticas públicas}

A análise de políticas públicas coloca em questão a ação pública do Estado, seus determinantes, suas finalidades, seus processos e suas consequências. Ao revelar os princípios políticos e ideológicos que norteiam a ação estatal, o tipo de relações estabelecidas entre os grupos demandantes, o papel exercido pelas instituições públicas, as práticas de governo instituídas e outras tantas variáveis que compõem essa complexa trama que é a construção de uma política, a análise de políticas pública possibilita maior transparência acerca do padrão político e decisório adotado pelo Estado (VIANA; BAPTISTA, 2009).

A análise de políticas públicas, de acordo com Labra (1999), consiste em um campo complexo, dinâmico e mutante, exigindo grande conhecimento teórico e de dados empíricos suficientes para que possa entender e explicar o que fazem os governos, como e por que o fazem. É clara a ideia que se trata de um assunto vasto e difícil de condensar e numerosos fatores corroboram para isso, dentre os quais se destacam as constantes mudanças das bases conceituais das formalizações, sendo preciso descrever novas variáveis,

à medida que os sistemas políticos e as sociedades se tornam mais complexos e se interpenetram por forças da transnacionalização das economias, da mundialização dos problemas sociais causados pelo atual padrão de acumulação capitalista e pelos acelerados avanços tecnológicos. (LABRA, 1999, P. 2).

Os estudos sobre análise de políticas iniciaram-se nos Estados Unidos, a partir de 1960, com a consolidação de programas de combate a pobreza, embora já se desenvolvessem pesquisas desde os anos 1950, com o uso de enquetes e da análise estatística, em uma perspectiva multidisciplinar, envolvendo as ciências sociais (PEREZ, 2006). Posteriormente, surgiu um novo campo definido como public policies, policy studies ou policy science, 
traduzido para o Brasil apenas como análise de políticas púbicas, voltado para analisar as relações entre governos, governantes e cidadãos. A preocupação com a explicação do processo político e a identificação de etapas distintas nesse processo surgiu, de acordo com Baptista e Rezende (2011), de forma paralela ao desenvolvimento do próprio campo de análise da política, em um contexto de busca de racionalização do Estado e da política pública.

No Brasil, os estudos de análise da política pública apresentam uma trajetória bastante recente, sendo esta uma área em consolidação e com escassa acumulação de conhecimento (VIANA; BAPTISTA, 2009). Segundo Labra (1999), no âmbito nacional, cada problema objeto de decisões e de resolução política, resulta de um conjunto de fenômenos que se traduzem em um processo de crescente setorialização, comportamentalização, de segmentação das políticas públicas e de tecnificação das decisões e de diversificação dos interesses envolvidos. A própria natureza da área política influi nas variáveis e dimensões relevantes para sua análise. Nesse contexto, não se pode dizer que exista um modelo acabado ou consensual para o estudo do processo de produção de uma determinada política, mas variadas correntes de pensamento ou abordagens que em muito contribuem para adicionar as revisões sobre o tema.

Dentre os principais modelos de formulação e análise de políticas públicas desenvolvidos para se entender melhor como e por que o governo faz ou deixa de fazer alguma ação que repercutirá na vida dos cidadãos, o método clássico é o ciclo da política, que divide o processo de uma política em etapas ou fases. Esse método originou-se de Harold Laswell, em 1951, em um contexto no qual a construção das políticas públicas era entendida a partir de uma lógica simples e linear, restrita ao âmbito governamental, e sem considerar o fato de o processo político e decisório ser um processo contínuo, interativo e complexo (BAPTISTA; REZENDE, 2011B). Posteriormente, outros analistas da política desenvolveram seus estudos, trazendo contribuições e sugerindo novos modelos, tendo como ponto de partida a identificação das características das agências públicas 'fazedoras da política'; dos atores participantes desse processo de 'fazer' políticas; das inter-relações entre agências e atores; e das variáveis externas que influenciam esse processo (VIANA, 1996).

Embora existam várias propostas de divisão do ciclo político, de um modo geral, são identificadas cinco etapas: 1) construção da agenda; 2) formulação de políticas; 3) processo decisório; 4) implementação de políticas e; 5) avaliação de políticas (NAJBERG; BARBOSA, 2006; VIANA; BAPTISTA, 2009; RIBEIRO, 2009). O ciclo da política pública considera o processo político como algo dinâmico, organizado no tempo e composto por etapas bem demarcadas e que permite, inclusive, possibilidades de aprendizagem com o próprio dinamismo do processo. Nesse sentido, a valorização deste modelo deve-se ao fato dele permitir estudar detalhadamente as diversas etapas envolvidas em um processo politico, e compreender como, em cada uma dessas etapas, as relações de poder, os processos decisórios e as relações entre os atores determinam as práticas político-administrativas (RIBEIRO, 2009).

Nesse modelo, prevalece a ideia de que

uma política se inicia a partir da percepção de problemas, passa por um processo de formulação de propostas e decisão, segue sendo implementada, para enfim ser avaliada e dar início a um novo processo de reconhecimento de problemas e formulação de política. (BAPTISTA; REZENDE, 2011A, P. 141).

Para estas autoras, a possibilidade de perceber que existem diferentes momentos no processo de construção de uma política, apontando para a necessidade de se reconhecer as especificidades de cada um desses momentos e possibilitando maior conhecimento e intervenção sobre o processo político talvez seja a principal contribuição da ideia do ciclo da política. 
Segundo Baptista e Rezende (2011B), apesar das críticas ao modelo (caráter funcionalista, racional e que tenta manter o controle sobre o processo político), o estudo dessas diferentes etapas da política ainda se apresenta como um recurso didático-metodológico importante para abordar a complexidade do processo de análise de políticas públicas e de referência no debate acadêmico.

Na perspectiva do ciclo da política, a primeira etapa constitui-se no momento de construção da agenda política, que trata da inclusão de um problema na relação de prioridades do poder público (MORAES, 2012). No âmbito da saúde, os problemas são socialmente construídos, ou seja, expressam "demandas de grupos sociais que conseguem, de algum modo, apresentar suas questões de maneira organizada e sensibilizar outros grupos para atender suas reivindicações" (PINTO; SILVA; BAPTISTA, 2014, P. 71).

Nessa perspectiva, os problemas se apresentam de maneira distinta e também ganham a atenção dos governos de modo diferenciado. Além disso, Baptista e Rezende (2011B) afirmam que os formuladores de políticas não conseguem atuar em todos os problemas o tempo todo e que apenas alguns temas são capazes de atrair a atenção dos formuladores e entrar na agenda decisória.

Um problema é considerado prioritário para integrar a agenda decisória quando mobiliza a ação política de grupos de interesse dotados de fortes recursos de poder, quando constitui uma ação de crise, calamidade ou catástrofe, ou quando representa uma situação de oportunidade (VIANA; BAPTISTA, 2009).

A definição da agenda consiste no espaço de constituição da lista de problemas ou assuntos que chamam a atenção do governo e dos cidadãos (VIANA; BAPTISTA, 2009; CARVALHO ET AL., 2010; SERAFIM; DIAS, 2012). Porém, a passagem de um problema para a agenda não é, por si só, um requisito definitivo para se elaborar uma política pública a fim de solucioná-lo. Para atingir o status de agenda decisória de governo, um assunto ou tema precisa, de acordo com Pinto et al. (2014), ser alvo de atenções e envolver a interação de uma série de elementos complexos, que incluem os participantes ativos (governamentais e não governamentais) e os processos pelos quais os problemas ganham prioridade. Esses processos, de acordo com Kingdon (1984) citado por Baptista e Rezende (2011B), incluem uma combinação de fluxos independentes que atravessam as estruturas de decisão - o fluxo de problemas (problem stream), o fluxo de soluções e alternativas (policy stream) e o fluxo da política (politics stream). Em algum momento, esses fluxos convergem criando 'janelas de oportunidade' (policy windows), que possibilitam a formação de políticas públicas ou mudanças nas políticas existentes. Destaca-se, aqui, o papel dos empreendedores de política (policy entrepreneurs) em promover determinadas propostas políticas. É nessa etapa da conformação da agenda que os conflitos referentes a qualquer processo de tomada de decisão estão sujeitos às influências daqueles que detêm o poder. Nesse sentido, um aspecto importante observado por Pinto, Silva e Baptista (2014) diz respeito ao fato de que em alguns casos, o entrelaçamento dos fluxos que promoveram a abertura da 'janela de oportunidade' para a tomada de decisão e formulação de uma política não é suficiente para garantir a implementação da proposta, seja pelo acirramento de conflitos entre os diversos grupos de interesse, seja pela ausência de convencimento dos que se opõem à proposta.

Seguindo a perspectiva do ciclo da política, a etapa seguinte à entrada do problema na agenda decisória de governo é a formulação da política, ou seja, o momento no qual, dentro do governo, se formulam soluções e alternativas para o problema, podendo ser entendido como o momento de diálogo entre intenções e ações (BAPTISTA; REZENDE, 2011B; PINTO; SILVA; BAPTISTA, 2014). Uma vez que o governo reconhece a existência de um problema e a necessidade de fazer algo sobre ele, os policy makers (fazedores de política), com base nas várias opções disponíveis para enfrentar o problema, precisam decidir ou não 
sobre um curso de ação. Inicia-se assim o processo de formulação da política pública (SERAFIM; DIAS, 2012). É na etapa de formulação que as opções são aceitas ou rejeitadas. É a tomada de decisão que abarca o processo de escolha, pelo governo, de soluções específicas, ou seja, é o momento em que se desenham as metas a serem atingidas, os recursos a serem utilizados e o horizonte temporal da intervenção (VIANA; BAPTISTA, 2009). Após a formulação da política, estão dadas as condições para a tomada de decisão, que abarca o processo de escolha pelo governo de uma solução específica ou uma combinação de soluções, em um dado curso de ação ou não ação. O resultado dessas etapas constitui-se na formalização das decisões por meio de medidas administrativas do legislativo (leis), do executivo (decretos, medidas provisórias e resoluções), e do judicial (interpretação das leis, entre outros), sendo essa a fase final do processo decisório (SERAFIM; DIAS, 2012).

As três etapas iniciais de construção da agenda, formulação de políticas e processo decisórios são importantes no ciclo da política, pois nelas serão definidos os princípios e diretrizes que nortearão as ações, desenhadas as metas a serem atingidas, os recursos a serem utilizados e o horizonte temporal da intervenção (PINTO; SILVA; BAPTISTA, 2014). No processo de formulação e decisão, segundo Viana e Baptista (2009), ainda há conhecimento limitado sobre o impacto efetivo das novas medidas propostas, o que explicaria muitas decisões serem adiadas para a etapa de implementação.

Dando continuidade ao ciclo da política, a etapa de implementação é, de acordo com Baptista e Rezende (2011B), a fase administrativa da política e envolve uma série de sistemas ou atividades da administração pública: o sistema gerencial e decisório, os sistemas de informação, os agentes implementadores da política, os sistemas logísticos e operacionais (recursos materiais, financeiros), dentre outros, que, segundo Viana (1996), acontecem em um espaço administrativo, por meio de um processo racionalizado de procedimentos e rotinas. Nesse sentido, a depender da complexidade e detalhamento na formulação da política, há necessidade de adequar a política à realidade, por parte dos atores implementadores, transformando as intenções em resultados observáveis. Por isso, essa etapa é considerada o momento de se colocar uma determinada solução em prática, de executar, dirigir, administrar, sendo, portanto, tratados como sinônimo de implementar (MENY; THOENIG, 1992 APUD NAJBERG; BARBOSA, 2006).

Contudo não se deve concluir que a etapa de implementação seja meramente uma etapa administrativa, pois envolve uma multiplicidade de questões estratégicas, políticas, interesses e atores. Nesse momento, para as autoras,

uma definição feita na etapa de tomada de decisão pode ser modificada ou mesmo rejeitada e alterar o argumento principal da própria política; novas negociações são processadas e, por consequência, novas decisões e formulações apresentadas. (VIANA; BAPTISTA, 2009, P. 77).

Tal como as conceituações sobre análise de políticas públicas, o processo de implementação de políticas também apresenta uma multiplicidade de concepções na literatura dedicada ao tema (PEREZ, 2006), apontando para a multideterminação e complexidade (THOENING, 1994; RUA, 1997; BARDACH, 1977 APUD NAJBERG; BARBOSA, 2006).

A implementação de políticas é vista como um processo de interação estratégica entre vários atores com diferentes interesses, sendo comparada a um jogo, no qual as relações se entrelaçam, envolvendo uma grande quantidade de jogadores, com suas estratégias e táticas, com variados graus de incertezas. Nessa perspectiva de jogo, uma autoridade central procura induzir agentes (implementadores) a colocar em prática os objetivos e estratégias que lhe são alheias, mas a resposta dos agentes implementadores, seja de aceitação, neutralidade ou rejeição, depende do entrosamento entre formuladores e implementadores, da compreensão da política, do 
conhecimento de cada fase do processo e da quantidade de mudança envolvida com a nova política. Para as autoras, este último fator apresenta-se como o mais crítico "porque determina os graus de consenso ou conflito em torno das metas e objetivos de uma política, e quanto maior a mudança, menor o consenso" (VIANA; BAPTISTA, 2009, P. 78).

Nas análises de implementação, destacam-se os enfoques top-down e botton-up, que assumem diferentes perspectivas. No enfoque top-down, segundo Baptista e Rezende (2011B), há o entendimento de que todo o controle está nas mãos dos 'formuladores', situados no topo das organizações, que assumem o controle dos fatores políticos, organizacionais e técnicos e a divisão de responsabilidades. Nessa concepção, os insucessos da implementação da política (em especial, a não consecução de objetivos e metas) são entendidos como desvios de rota cometidos por atores no nível local, que não foram capazes de executar a política da maneira exata como foi estabelecida.

Nessa perspectiva, o papel dos gestores e o desenho institucional da política se tornam críticos, em função dos atores envolvidos (os agentes que implementam a política e o público-alvo do programa), dos instrumentos estabelecidos e do grau de centralização dos processos (existência de um órgão especifico ou não, mecanismos de supervisão, especialização das organizações, entre outros). Para Ribeiro (2009), a forma regulatória como a política é absorvida nas organizações e o modo como as diretrizes e orientações são postas em prática, determinam o nível de qualidade dos resultados e mesmo a eficácia dos efeitos planejados. Essa referência faz relação com o modelo top-down, em que se espera dos implementadores o cumprimento das ações planejadas nas etapas de decisão tratando as inconsistências como desvio de rota, como abordaremos a seguir (SILVA; MELO, 2000).

O enfoque denominado botton-up constituiu-se a partir de críticas ao enfoque topdown e parte da análise das redes de decisões que se estabelecem no nível concreto de sua execução, no enfrentamento entre os diversos atores quando da implementação (PINTO; SILVA; BAPTISTA, 2014). De acordo com Baptista e Rezende (2011B), esse enfoque baseia-se na ideia de que existe sempre um controle imperfeito em todo o processo de elaboração da política, o que condiciona o momento da implementação. Esse modelo fundamenta-se em uma abordagem que assume a implementação como um processo caracterizado por um estado de tensão entre aqueles interessados em colocar a política em ação e aqueles que serão afetados por ela. A implementação, do mesmo modo que a formulação é um processo caracterizado por intensa negociação entre as partes interessadas e, por isso mesmo, o controle não está totalmente nas mãos do formulador, nem totalmente nas mãos do implementador. Nesse caso, o insucesso na implementação da política é entendido como incapacidade de negociação durante o processo (RIBEIRO, 2009).

As críticas aos enfoques top-down e botton-up levaram à constituição de uma nova geração de estudos, que revelaram novos modelos multicausais capazes de combinar questões estratégicas, política, múltiplos atores e interesses como opções de análise nos estudos de implementação (PINTO; SILVA; BAPTISTA, 2014; BAPTISTA; REZENDE, 2011B).

A última etapa do ciclo da política é a avaliação, entendida como ferramenta ou instrumento técnico útil para a formulação da política e que, segundo Baptista e Rezende (2011A, P. 153),

tem sido amplamente debatida na literatura pelas distintas concepções atribuídas à própria ideia de avaliação, bem como pelos diversos caminhos metodológicos traçados, em função daquilo que está sendo avaliado e dos objetivos que se pretende alcançar.

A avaliação, segundo Pinto, Silva e Baptista (2014), é um dos tipos de julgamento possíveis que se faz sobre as práticas sociais, compreendidas desde as práticas cotidianas e do 
trabalho até aquelas que correspondem às intervenções, formalizadas ou não em planos e programas, voltadas para a mudança de uma determinada situação.

No âmbito de uma política de saúde, a avaliação é um julgamento de valor a respeito de uma intervenção ou sobre qualquer um dos seus componentes com o objetivo de auxiliar na tomada de decisões. Trata-se da etapa do processo de monitoramento dos resultados, pelo governo ou outro tipo de organização, que visa avaliar a política implementada e reconduzir os seus cursos. Embora seja apontada no ciclo da política como uma etapa específica, a avaliação tem sido utilizada como um instrumento voltado para subsidiar a tomada de decisões nos mais variados momentos que ocorrem ao longo das diversas etapas do ciclo, não se restringindo à avaliação de resultados da política e nem à etapa final do processo (BAPTISTA; REZENDE, 2011B).

Nessa compreensão, o momento do ciclo da política ao qual a avaliação se remete é, de acordo com Baptista e Rezende (2011B), um elemento determinante dos diferentes tipos de avaliação, e uma das tipologias utilizadas é a distinção entre avaliações ex-ante e ex-post.

Segundo Viana e Baptista (2009), os estudos de avaliação são de tipo específico e compreendem a pesquisa avaliativa e a avaliação propriamente dita. A pesquisa avaliativa consiste em fazer um julgamento após uma intervenção (ex-post) por pesquisadores exteriores à intervenção, utilizando métodos científicos a fim de analisar a pertinência, os fundamentos teóricos, a produtividade, os efeitos e o rendimento de uma intervenção, objetivando ajudar na tomada de decisões (avaliações-diagnóstico). Essa etapa pode se apresentar no início do ciclo ou ao longo dele, de forma concomitante, e não apenas após a implementação da política. O objetivo dessa etapa é proceder à revisão e medição sistemática do problema. Como resultado, pode ocasionar três situações: a) auxiliar na melhoria da política; b) finalizar a política existente e 3) desenvolver uma nova política
(SERAFIM; DIAS, 2012). Por outro lado, a avaliação propriamente dita é a atividade que consiste em fazer um julgamento sobre uma intervenção, comparando os recursos empregados e sua organização (avaliação de estrutura), os serviços e bens produzidos (avaliação de processo) e os resultados obtidos (avaliação de impacto), com critérios e normas.

De modo geral, conforme Viana e Baptista (2009), existem estudos de avaliação que se realizam na etapa de formulação e tomada de decisão política, denominadas de avaliações ex-ante, que ocorrem antes da implementação e compreendem o cálculo do custo-benefício e do custo-efetividade, visando subsidiar os formuladores de política sobre informações a respeito das possibilidades e alcance dos recursos a serem empregados. Por sua vez, as avaliações de estrutura e de processo estudam a etapa de implementação de determinada política e a avaliação de impacto estuda o efeito dos resultados. São consideradas avaliações ex-post por ocorrerem durante e depois da etapa de implementação, possibilitando a compreensão do desenvolvimento estratégico e a definição de novos rumos da política.

Os objetivos da avaliação dependem de quem formula a pergunta. Nesse entendimento, as práticas sociais, incluindo a gestão de serviços de saúde, podem ser orientadas por determinantes com diferentes racionalidades, como, por exemplo, a avaliação pode responder a necessidade de legitimação por parte dos gestores, de modo a retardar a tomada de decisões, a aumentar o controle sobre a intervenção e a satisfazer as exigências dos organismos financiadores (PINTO, SILVA; BAPTISTA, 2014).

Nesse ponto, é relevante discutir a diferença entre 'avaliação política', 'análise de políticas públicas' e 'avaliação de políticas públicas'. De acordo com Baptista e Rezende (2011B), a 'avaliação política' é compreendida como a análise e elucidação do critério ou critérios que fundamentam determinada política esclarecendo as razões que a tornam preferível a qualquer outra, podendo ressaltar 
tanto o caráter político do processo decisório quanto os valores e critérios políticos identificáveis. Esse tipo de avaliação examina os pressupostos e fundamentos políticos de um determinado curso de ação pública, independentemente de sua engenharia institucional e seus resultados prováveis.

Por sua vez, para essas autoras, a 'análise de políticas públicas' visa realizar o exame da engenharia institucional e dos traços constitutivos do programa, que podem ser formulados e implementados de diversos modos. Assim, busca reconstituir suas características de forma a apreendê-las em um todo coerente e compreensível, dando sentido e entendimento às ambiguidades, incoerências e incertezas presentes em todos os momentos e estágios da ação pública. Aproxima-se da avaliação de processos à medida que permite identificar os fatores facilitadores e os obstáculos que operam ao longo da implementação, sem se preocupar diretamente com os resultados. Essa análise consiste em um conjunto de procedimentos significativamente complexos e exige um posicionamento ideológico claro por parte do analista, atentando para elementos de natureza mais sutil, cuja preocupação central é o processo da política, com ênfase em aspectos, como valores e os interesses dos atores envolvidos no jogo político, como a interação entre esses atores, como a arquitetura do poder e a tomada de decisões, conflitos e negociações. A análise pauta-se fortemente na apreciação dos processos que, em última instância, determinam as características gerais da política (SERAFIM; DIAS, 2012).

A atribuição da relação de causalidade entre a política e o resultado é o objetivo da 'avaliação de políticas públicas'. Sua particularidade consiste, segundo Baptista e Rezende (2011B), na adoção de métodos e técnicas de pesquisa que permitam estabelecer tal relação, ou ainda estabelecer que na ausência deste programa não houvesse o resultado mencionado, sendo clara a ligação dessa modalidade avaliativa com a avaliação de resultados.
Nesse sentido, a avaliação fundamenta-se na apreciação dos resultados da política, ou ainda nas ações, programas e projetos, focando em categorias como eficiência, eficácia e efetividade, que derivam da comparação entre metas e resultados (SERAFIM; DIAS, 2012).

Uma questão que ainda se faz necessária diz respeito às pesquisas no âmbito da análise de políticas públicas, que, de modo geral, se concentram nos processos de tomada de decisão e no momento de construção de uma dada política ou de um grupo de políticas (VIANA; BAPTISTA, 2009), raramente abordando o processo de implementação e restringindo suas análises nos níveis mais altos da decisão, com pouca vinculação e atenção aos demais níveis hierárquicos (PEREZ, 2006). Para Silva e Melo (2000), os fracassos de programas governamentais estão fortemente relacionados às dificuldades enfrentadas durante a implementação das políticas públicas. Por isso, defendem o ponto de vista de que os processos de análise de politicas públicas devem atentar, especialmente, para os processos de implementação. Assim, é fundamental essa discussão, em nível da microgestão do governo, no âmbito do processamento da política, uma vez que é no nível local que os ajustes são realizados para alcançar as prerrogativas antes desenhadas pelos fazedores de políticas.

Na perspectiva da complexidade de elementos que convergem na etapa de implementação e sua importante contribuição para a análise de políticas, faz-se necessário maior aprofundamento dessa etapa, a fim de buscar entender o processo político de forma mais dinâmica e interativa.

\section{$O$ processo de implementação de políticas públicas}

O momento da implementação está relacionado à etapa de formulação da política, na qual, segundo Hogwood e Gunn citado por Viana e 
Baptista (2009, P. 78), "há uma tendência a constituir pactos políticos abrangentes, sem uma especificação da política a ser implementada, ou dos pré-requisitos que a sustentam".

A implementação é, para Viana e Baptista (2009), o momento de intensa negociação no qual se observa a sustentabilidade dos pactos estabelecidos na etapa de formulação, revelando-se a real possibilidade de uma política, quem são os atores que a apoiam, o que cada um dos grupos disputa e seus interesses. Além disso, para essas autoras,

estabelecem-se novos pactos, agora com novos atores, muitas vezes não-participantes do pacto inicial de formulação, como os atores responsáveis pela prestação direta de serviços e que são, na ocasião da implementação, os principais agentes da política. (VIANA; BAPTISTA, 2009, P. 78).

Nessa perspectiva, inicia-se

um novo processo decisório, uma nova formulação da política, agora voltada para sua aplicabilidade mais imediata e já não mais sujeita a intervenções ampliadas dos grupos sociais que sustentaram a proposta previamente agendada. (VIANA; BAPTISTA, 2009, P. 79).

A etapa de implementação de uma política é considerada seu "momento crucial, onde as propostas se materializam em ação institucionalizada mediante a atuação dos agentes implementadores" (PINTO; SILVA; BAPTISTA, 2014, P. 73). Esse tem sido um aspecto crítico de discussão da análise de políticas públicas, no qual, segundo Viana e Baptista (2009, P. 78),

a etapa de implementação tem merecido destaque na tentativa de melhor compreender por que os governos são muito melhores para fazer a legislação do que para efetuar as mudanças desejadas

e, por isso, tem sido entendida como a variável central para a explicação do insucesso dos governos em atingir os objetivos estabelecidos no desenho de políticas públicas. Essa constatação tem chamado a atenção para a centralidade dos problemas de implementação de políticas como elemento-chave no aperfeiçoamento da ação governamental. Apesar da importância para o sucesso prático da ação do governo, o processo de implementação tem sido considerado o 'elo perdido' da análise da ação governamental (IILVA; MELO, 2000).

Ao debruçar-se sobre as razões que justificam o reconhecimento da etapa da implementação como o 'elo perdido', alguns estudos sobre as políticas destacam o reconhecimento tardio da importância da implementação de políticas públicas devido ao fato de seus estudiosos possuírem um viés tradicional das ciências políticas, focado na análise dos processos legislativos ou administrativos do executivo (CARVALHO ET AL., 2010).

Outro aspecto importante é o fato de que as ações governamentais pouco exploram essa etapa do ciclo da política, que segundo Viana e Baptista (2011), diz respeito ao baixo compromisso dos políticos com o momento de implementação, aceitando que lhes caiba o ônus da formulação, do qual prestam contas. Nesse contexto, problemas não antecipados e/ou desconsiderados que surgem durante a implementação da política podem representar obstáculos intransponíveis, os quais, por sua vez, podem levar a sua descontinuidade (SILVA; MELO, 2000). Nesse sentido, Carvalho et al. (2010) afirmam que um grave problema da formulação, que não é vista como problemática, é considerar o diagnóstico como necessariamente correto e que o formulador dispõe das informações suficientes para desenhar a proposta da política. Além disso, é reconhecida uma divisão institucionalizada entre aqueles que formulam e os que implementam uma política, sendo estes últimos capazes de identificar os pontos-chave da operacionalização devido ao seu conhecimento técnico (VIANA; BAPTISTA, 2009). Com esse entendimento, ressalta-se o trabalho de Pressman e Wildavsky apud Ribeiro (2009) que alerta para os 'contratempos' vivenciados durante a etapa de implementação e chama a 
atenção para a necessidade de estudos específicos sobre essa etapa. Caso a implementação de uma política dependa das ações de muitos atores, em muitas instâncias, o nível de aceitação e colaboração de cada um deles deve ser total, para que a implementação ocorra conforme foi planejada. Caso haja, em qualquer das instâncias, uma colaboração menor do que a necessária haverá o que Wildavsky chama de déficit de implementação. A cumulação de déficits de implementação colocará os objetivos da política em risco, ou, na melhor das hipóteses, diminuirá os efeitos dos resultados previstos quando da formulação da política. Nesse caso, a implementação é a etapa marcada pela imprevisibilidade e, portanto, pela perda de controle por parte do formulador da política, pois não é possível prever todas as situações envolvidas no processo de implementação de uma política (CUNHA, 2001).

Com relação aos problemas de implementação, no contexto prático da vida cotidiana, um aspecto relevante diz respeito à alta complexidade do processo de implementação de uma política e, sobretudo, a sua capacidade de gerar consequências sobre o funcionamento das organizações de saúde, especialmente nos municípios de pequeno porte. De acordo com Viana e Baptista (2009), a própria complexidade desse processo demanda um conhecimento sólido e prévio das múltiplas variáveis que influem no processo político e que, por mais controladas que sejam, apresentam um comportamento independente, não linear. Nesse sentido, a análise da etapa de implementação não é tarefa fácil, seja por conta do número de atores envolvidos, seja pela quantidade de tarefas a serem executadas, em um curto espaço de tempo. Por isso a importância de acompanhamento minucioso desta etapa, visando superar as barreiras e resistências que operam em tais situações, bem como identificando aspectos e situações que eventualmente necessitem de ajustes e correções por parte dos formuladores da política (RIBEIRO, 2009).

Aprofundando a reflexão sobre os problemas na etapa de implementação, destaca-se a grande atenção dispensada à etapa de avaliação do processo de implementação, em detrimento da análise de implementação, na qual se adota um posicionamento voltado para o alcance ou não alcance dos resultados definidos na etapa de elaboração da política. Importante reafirmar que avaliação e análise, embora explorem o mesmo objeto central, a política pública, constituem-se em exercícios distintos (CAVALCANTE, 2005). Outro aspecto a ser ressaltado diz respeito ao campo de análise de políticas públicas, que ainda permanece centrado nos processos decisórios, não atentando para o processo de implementação (FARIA, 2003).

O diagnóstico sobre a implementação como ‘elo perdido', segundo Silva e Melo (2000), está ancorado em uma visão inadequada do processo de formulação e implementação de políticas, e baseia-se na abordagem top-down ou botton-up. Esses autores trazem uma reflexão sobre os modelos de análise do ciclo de políticas. O primeiro deles é o modelo clássico. Esse modelo considera os aspectos relacionados à etapa de implementação e os seus efeitos retroalimentadores sobre a formulação da política, ou seja, essa visão não considera o ciclo da política como um processo, mas sim como um jogo de uma só rodada em que a ação governamental é implementada de cima para baixo (top-down). Nessa visão, a implementação corresponde à execução de atividades que permitem que ações sejam implementadas com o objetivo de atingir as metas definidas nas etapas anteriores, como um processo preestabelecido, com regras e procedimentos bem definidos, em que os formuladores têm total controle do processo. Nesse caso, o insucesso na implementação significa que, em algum ponto do processo, os procedimentos foram mal executados ou mal-entendidos. Essa visão simples é criticada porque não considera toda a dinâmica que se estabelece na relação entre os indivíduos e entre os grupos, os conflitos de interesses e a capacidade de influencia que cada ator ou grupo exerce sobre o processo de implementação (RIBEIRO, 2009). Para Silva e Melo (2000), a adoção dessa 
perspectiva pressupõe um olhar ingênuo e irrealista do funcionamento da administração pública e consagra uma visão top-down da formulação e desenho dos programas, em que os problemas de implementação são vistos como 'desvios de rota'.

No modelo menos simplista, no qual a formulação e a implementação são vistas como um processo, a implementação é tratada como dimensão importante e complexa (botton-up). Nesse processo, propõe-se que o monitoramento e avaliação sejam instrumentos que permitirão correção de rota. As vivências, obstáculos e problemas identificados na implementação são resultados relacionados à capacidade institucional dos agentes implementadores da política. Outra questão a ser destacada é que, na implementação dos programas, esses problemas são de natureza política e podem ser derivados da resistência e boicotes realizados por aqueles que são afetados negativamente pela política (SILVA; MELO, 2000).

Essa perspectiva de análise do ciclo da política como um processo representa, segundo Silva e Melo (2000), um avanço em relação ao modelo anterior, porém, ela se assenta em uma premissa equivocada ao conferir uma primazia excessiva à atividade de formulação, assumindo que o diagnóstico que informa a formulação está essencialmente correto, o formulador dispõe de todas as informações necessárias ao desenho das propostas programáticas, e o formulador dispõe de um modelo causal válido. Como crítica a esses dois modelos, estudos de situações concretas propõem que a implementação deva ser vista com um jogo no qual prevalecem, enquanto princípios organizadores, a troca, negociação e barganha, dissenso e a contradição quanto aos objetivos. Assim, a etapa da implementação pode ser representada "como um jogo entre implementadores onde papéis são negociados, os graus de adesão ao programa variam, e os recursos entre atores são objeto de barganha" (SILVA; MELO, 2000, P. 10).

Embora o grande número de referenciais sobre políticas de saúde seja americano, Silva e
Melo (2000), chamam a atenção para a especificidade do contexto institucional e organizacional brasileiro, dentre as quais destacam-se a sua complexidade e forte diferenciação funcional, e principalmente os problemas de coordenação e cooperação intergovernamental.

Ressalta-se ainda, segundo Silva e Melo (2000), a importância do reconhecimento do jogo político como essencial à vida democrática e fundamental para o controle social da ação do governo. Nesse sentido, a implementação passa a estar fortemente imbricada em estruturas de governança, entendida enquanto regras do jogo e arranjos institucionais que dão sustentação à cooperação, coordenação e negociação.

O que é comum a essas contribuições é a recusa à noção de implementação como uma simples etapa subsequente à formulação. A implementação é aqui entendida como uma instância racional e compreensiva, um processo autônomo no qual decisões cruciais são tomadas e não somente 'implementadas'. Nesse sentido, o agente implementador toma as decisões de uma política setorial de tal forma, que a adesão normativa do agente implementador é variável decisiva do seu sucesso. Logo, a implementação 'cria' políticas e, constantemente, orienta novas políticas. Além disso, como a implementação implica em tomada de decisões, constitui-se fonte de informações para a formulação de políticas (SILVA; MELO, 2000).

Nessa perspectiva, a ideia de avaliação como instrumento de correção de rota deve ser substituída pela noção do aprendizado na implementação de uma política pública, que enfatiza a aprendizagem, evolução, adaptação e a implementação como decisão política, em ambientes institucionais democráticos e descentralizados. Alguns problemas da implementação são discutidos como elementos centrais dessas contribuições, em que se deve consolidar a ideia de que é necessário ter uma visão estratégica dos problemas de implementação, bem como a incorporação de questões críticas, como a viabilidade política de políticas e os problemas de coordenação 
interorganizacional. Esse novo desenho estratégico deve incluir a identificação de redes complexas de atores, compostas por formuladores, implementadores, grupos de pessoas envolvidos na política e beneficiários, que dão sustentação política e legitimidade.

Nesse sentido, o conceito de implementação como rede de aprendizado mostra-se mais apropriado, pois as políticas públicas são implementadas por meio de redes de agentes públicos e não públicos. O ciclo da política, nessa perspectiva, não pode ser concebido de forma simples e linear, sendo melhor representado por redes complexas, compostas por atores que dão sustentação à política e por 'nós críticos' ou 'elos críticos', que

representam os pontos no tempo onde questões referidas ao processo de sustentação política dos programas, de coordenação interinstitucional e de capacidade de mobilizar recursos institucionais se conjugam. (SILVA; MELO, 2000, P. 14).

Nesse momento de conjugação, para esses autores, produz-se uma espécie de 'crise', concretizada no processo de tomada de decisão por um ator estratégico, cujo desenlace impele o programa em uma nova direção. Assim, a visão da implementação enquanto aprendizado e articulada em uma rede de atores constitui um quadro de referências que permite uma representação mais consistente dos mecanismos de implementação de políticas.

\section{Considerações finais}

A operacionalização da política apresenta inúmeros entraves no nível local permeados por questões estratégicas, por interesses e por múltiplos atores, considerados aspectos determinantes para o sucesso ou insucesso da política. Nesse sentido, a ideia de implementação de políticas não pode ser restrita ao cumpra-se da política nem ao pressuposto de que a decisão da autoridade pode ser automaticamente cumprida.
Analisar o processo de implementação representa a oportunidade de compreender os processos implicados para alcance dos efeitos esperados na etapa de elaboração da política e aponta para dimensões cruciais no sentido de explicar os insucessos dos governos em atingir os objetivos definidos na etapa de definição da política, podendo constituir-se em um processo de aprendizagem.

Nesse sentido, a implementação deve ser reconhecida como uma etapa fundamental dentro da análise de políticas pública, sendo primordial buscar analisar como os arranjos locais se comportam frente a uma determinação governamental para implementar ações, programas e políticas. Compreender o que leva os agentes implementadores de políticas a torná-las realidade, objetivando serem efetivas e alcançar os objetivos formulados consiste em uma análise complexa que merece ser difundida e discutida amplamente, de forma que seja incorporada pelos analisadores de política e possam colaborar para solucionar entraves que dificultam a implementação de políticas públicas, bem como reforçar as estratégias e experiências de sucesso. Nessa perspectiva, o ciclo da política deve ser entendido como um processo contínuo, sem um fim definido ou produtos finais, em que os conflitos, frutos da implementação, podem ou não manifestar-se em um novo padrão de comportamento nas instituições.

A elaboração e aplicação de metodologias de análise que deem conta da complexidade desse campo e que apreendam o desenho de estruturas de incentivo que promovam arranjos cooperativos em redes de implementação merecem ser discutidas e reforçadas, para além de instrumentos de avaliação para correção de rota, como instrumentos analisadores estruturados que promovam discussões de caráter estratégico e possibilitem reflexões sobre os determinantes da política pública. Por fim, resgatar a etapa da implementação desvendando esse 'elo perdido' ao ponto de conferir a ele uma posição chave dentre do processo da política mostra-se como o caminho para fortalecer a ação governamental. 


\section{Referências}

ARRETCHE, M. Financiamento federal e gestão local de políticas sociais: o difícil equilíbrio entre regulação, responsabilidade e autonomia. Ciênc. saúde coletiva, Rio de Janeiro, v. 8, n. 2, 2003. Disponível em: <http://www.scielo.br/scielo.php?script=sci arttext\&pid $=$ S1413-81232003000200002\&lng $=$ en\&nrm =iso>. Acesso em: 11 nov. 2013.

BAPTISTA, T. W. F.; REZENDE, M. A ideia de ciclo na análise de políticas públicas. In: MATTOS, R. A.; BAPTISTA, T. W. F. (Org.). Caminhos para análise das políticas de saúde. 2011a. p. 138-172. Disponível em: <www. ims.uerj.br/pesquisa/ccaps>. Acesso em: 25 set. 2013.

BAPTISTA, T. W. F; MATTOS, R. A. Sobre Política (ou o que achamos pertinente refletir para analisar políticas). In: MATTOS, R. A.; BAPTISTA, T. W. F. (Org.). Caminhos para análise das políticas de saúde. 2011b. p. 52-91. Disponível em: <www.ims.uerj.br/pesquisa/ ccaps $>$. Acesso em: 25 set. 2013.

BOBBIO, N.; MATTEUCI, N.; PASQUITO ,G. Dicionário de Política. 1l. ed. Brasília, DF: UnB. 1998.

CARVALHO, M. L. et al. Implementação de política pública: uma abordagem teórica e crítica. X Colóquio Internacional sobre Gestión Universitaria em América del Sur. Balance y propoectiva de la Educación Superior em el marco de los Bicentenarios de Amércia del Sur. Mar del Plata, dezembro de 2010. Disponível em: < https://repositorio.ufsc.br/bitstream/handle/123456789/97020/ IMPLEMENTA\%C3\%87\%C3\%830\%20DE\%20 POL\%C3\%8DTICA\%20P\%C3\%9ABLICA\%20 UMA\%20ABORDAGEM\%20TE\%C3\%93RICA\%20 E\%20CR.pdf?sequence=1>. Acesso em: 23 maio 2013.

CAVALCANTI, P. A. O conceito de avaliação de políticas, programas e projetos. In: PEREZ, J. R. R. et al. (Org.). Estudo, pensamento e criação: planejamento educacional e avaliação na escola. Campinas: Unicamp, 2005.

COHN, A. O estudo das políticas de saúde: implicações e fatos. In: CAMPOS, G. W. S. et al. Tratado de Saúde Coletiva. São Paulo: Hucitec; Rio de Janeiro: Ed. Fiocruz, 2009. p. 219-246.

CONTARATO, P. C. Política nacional e contexto local: uma análise da implementação da Política de Saúde
Bucal no município de Vitória, do Espírito Santo. 163 p. 2011. Dissertação (Mestrado em Ciências) - Escola Nacional de Saúde Pública Sérgio Arouca, Fundação Oswaldo Cruz. Rio de Janeiro, 2011.

CUNHA, E. M. Regra e realidade na constituição do SUS municipal: implementação da NOB 96 em Duque de Caxias. 2001. 144 f. Dissertação (mestrado em Saúde Pública) - Fundação Oswaldo Cruz, Escola Nacional de Saúde Pública. Disponível em: <http://portalteses.icict. fiocruz.br/transf.php?script=thes_cover\&id $=000054 \& 1$ ng=pt\&nrm=iso>. Acesso em: 02 fev. 2014.

FARIA, C. A. P. Ideias, conhecimento e políticas públicas: um inventário sucinto das principais vertentes analíticas recentes. Revista Brasileira de Ciências Sociais, São Paulo, v. 18, n. 51, p. 21-30, fev. 2003. Disponível em: <http://www.scielo.br/pdf/rbcsoc/v18n51/15984.pdf>. Acesso em: 02 fev. 2014.

FLEURY, S.; OUVERNEY, A. M. Política de saúde: uma política social. In: GIOVANELLA, L. et al. (Org.). Políticas e Sistema de Saúde no Brasil. Rio de Janeiro: Ed. Fiocruz, 2008. p. 23-64.

LABRA, M. E. Análise de políticas, modos de policy-making e intermediação de interesses: uma revisão. Physis, Rio de Janeiro, v. 9, n. 2, dez. 1999. Disponível em: <http://www.scielo. br/scielo.php?script=sci_arttext\&pid=S0103$-73311999000200008 \& \operatorname{lng}=e n \& n r m=i s o>$. Acesso em: 05 mar. 2013.

LOPEZ, S. B.; MOREIRA, M. C. N. Quando uma proposição não se converte em política?: O caso da Política Nacional de Atenção Integral à Saúde de Adolescentes e Jovens - PNAISAJ. Ciênc. saúde colet., Rio de Janeiro, v. 18, n. 4, abr. 2013. Disponível em: <http://www.scielo.br/scielo.php?pid=S141381232013000400031\&script=sci_arttext $>$. Acesso em: 30 nov. 2013.

MARQUES, R. M.; MENDES, A. Atenção Básica e Programa de Saúde da Família (PSF): novos rumos para a política de saúde e seu financiamento? Ciênc. saúde. colet., Rio de Janeiro, v. 8, n. 2, 2003. Disponível em: $<$ http://www.scielo.br/scielo.php?script=sci arttext\&pid=S1413-81232003000200007\&lng=en\&nrm= iso>. Acesso em: 25 nov. 2013. 
MORAES, K. G. Análise do processo de implementação da política de educação permanente em saúde no Distrito Federal. 2012. 140 f. Dissertação (Programa de Pós Graduação em Enfermagem) - Departamento de Enfermagem, Faculdade de Ciências da Saúde, Universidade Federal de Brasília, Brasília, 2012.

NAJBERG, E.; BARBOSA, N. B. Abordagens sobre o processo de implementação de políticas públicas. Revista do Centro de Ciências Sociais Aplicadas, São Paulo, v. 3, n. 2, jul/dez. 2006. p. 31-45. Disponível em: $<$ http://encontroamericalatina.ccsa.ufrn.br/ojs/index. php/interface/article/view/203/181>. Acesso em: 04 jun. 2013.

PAIM, J. S; TEIXEIRA, C. F. Política, planejamento e gestão em saúde: balanço do estado da arte. Revista de Saúde Pública, São Paulo, v. 40, n. especial, p. 73-78, 2006.

PEREZ, J. R. R. Avaliação do processo de implementação: algumas questões metodológicas. In: RICO, E. M. (Org). Avaliação de políticas sociais: uma questão em debate. Editora Cortez. 6. ed. São Paulo. 2006, p. 65-73.

PINTO, I. C. M.; SILVA, L. M. V.; BAPTISTA, T. V. F. Ciclo de uma política pública de saúde: problematização, construção da agenda, institucionalização, formulação, implementação e avaliação. In: PAIM. J. S.; ALMEIDA-FILHO, N. Saúde coletiva: teoria e prática. Rio de Janeiro: MedBook, 2014. p. 69-81.

RIBEIRO, J. L. L. S. A avaliação como uma política pública: aspectos da implementação do SINAES. In: LORDÊLO, J. A. C.; DAZZANI, M. V. (Org.). Avaliação educacional: desatando e reatando nós. Salvador: EDUFBA, 2009. p. 57-84. Disponível em: $<$ http://static.scielo.org/scielobooks/wd/pdf/lordelo-9788523209315.pdf>. Acesso em: 10 dez. 2013.
SERAFIM, M., DIAS, R. Análise de política: uma revisão da literatura. Cadernos Gestão Social, Salvador, v. 3, n. 1, maio 2012. Disponível em: <http://www.periodicos.adm.ufba.br/index.php/cgs/article/view/213>. Acesso em: 04 jun. 2013.

SILVA, P. L. B; MELO, M. A. B. O processo de implementação de políticas públicas no Brasil: características e determinantes da avaliação de programas e projetos. UNICAMP. 2000. Disponível em: <http://governancaegestao.files.wordpress.com/2008/05/teresa-aula_22. pdf $>$. Acesso em: 15 jun. 2013.

\section{SOLLA, J. Dilemas e Desafios da gestão municipal do} SUS. São Paulo: Ed. Hucitec, 2010.

SOUZA, C. Políticas públicas: uma revisão da literatura. Sociologias, Porto Alegre, n. 16, dez. 2006. Disponível em: <http://www.scielo. $\mathrm{br} /$ scielo.php?script=sci_arttext\&pid=S1517$-45222006000200003 \& \operatorname{lng}=\mathrm{pt} \& \mathrm{nrm}=\mathrm{iso}>$. Acessos em: 20 jun. 2013.

VIANA, A. L. Abordagens metodológicas em políticas públicas. Revista de Administração Pública, Rio de Janeiro, v. 30, n. 2, p. 5-43, mar./abr. 1996.

VIANA, L. A.; BAPTISTA, T. W. F. Análise de políticas de Saúde. In: GIOVANELLA, L. (Org.). Políticas e Sistema de Saúde no Brasil. Rio de Janeiro: Ed. Fiocruz, 2009. p. 65-105.

\footnotetext{
Recebido para publicação em abril de 2014

Versão final em dezembro de 2014

Conflito de interesses: inexistente

Suporte financeiro: não houve
} 